\title{
Sorption Efficiency of Chitosan Nanofibers toward Metal lons at Low Concentrations
}

\author{
Nesrin Horzum,${ }^{\dagger}$ Ezel Boyacı, ${ }^{\dagger}$ Ahmet E. Eroğlu, ${ }^{\dagger}$ Talal Shahwan, ${ }^{\dagger, \ddagger}$ and \\ Mustafa M. Demir ${ }^{*},+$ \\ Department of Chemistry, izmir Institute of Technology, Izmir, Turkey, and Department of Chemistry, \\ Birzeit University, Ramallah, West Bank, Palestine
}

Received July 7, 2010; Revised Manuscript Received October 28, 2010

\begin{abstract}
Chitosan fibers showing narrow diameter distribution with a mean of $42 \mathrm{~nm}$ were produced by electrospinning and utilized for the sorption of $\mathrm{Fe}(\mathrm{III}), \mathrm{Cu}(\mathrm{II}), \mathrm{Ag}(\mathrm{I})$, and $\mathrm{Cd}(\mathrm{II})$ ions from aqueous solutions. The ion concentrations in the supernatant solutions were determined using inductively coupled plasma-mass spectrometry (ICP-MS). The filtration efficiency of the fibers toward these ions was studied by both batch and microcolumn methods. High efficiency in sorption of the metal ions was obtained in the both methods. The effects of sorbent amount $(0.10-0.50 \mathrm{mg})$, shaking time $(15-120 \mathrm{~min})$, initial metal ion concentration $\left(10.0-1000.0 \mu \mathrm{g} \cdot \mathrm{L}^{-1}\right)$, and temperature $\left(25\right.$ and $50{ }^{\circ} \mathrm{C}$ ) on the extent of sorption were examined. The sorbent amount did not significantly alter the efficiency of sorption; however, shaking time, temperature, and metal ion concentration were found to have a strong influence on sorption. By virtue of its mechanical integrity, the applicability of the chitosan mat in solid phase extraction under continuous flow looks promising.
\end{abstract}

\section{Introduction}

Ground water pollution originating from both natural and anthropogenic sources forms a detrimental problem to the environment. Metal ions are released into the environment from a variety of natural sources including mineral and metallic deposits in sedimentary rocks and soil. Man-made activities such as mining, plating, glass making, ceramics, and battery manufacturing also lead to a great increase in heavy metal contamination in water, causing an ongoing risk to the biosphere. Cadmium, for instance, is one of the most toxic metals for the biosystems that accumulates in the human body, especially in the kidneys. The intake of overdoses of cadmium has been reported to cause renal diseases, prostate cancer, and bone lesions. ${ }^{1}$ Excessive intake of copper, as another example, causes damages to liver, kidneys, and intestinal system. ${ }^{2}$ Moreover, iron in drinking water or water supplies bring about problems regarding the quality of water such as providing reddish color, metallic taste, and odor. ${ }^{3}$ When silver or its compounds come into contact with the skin, they may cause permanent discoloration known as argyria. Although $\mathrm{Cu}$ and $\mathrm{Fe}$ are essential elements for living organisms, they become potentially toxic at higher concentrations; thus, their contents must be kept at certain threshold levels. The maximum contamination levels (MCL) in drinking water set by the Environmental Protection Agency (EPA) are $0.005 \mathrm{mg} \cdot \mathrm{L}^{-1}$ for cadmium, $1.3 \mathrm{mg} \cdot \mathrm{L}^{-1}$ for copper, $0.3 \mathrm{mg} \cdot \mathrm{L}^{-1}$ for iron, and $0.05 \mathrm{mg} \cdot \mathrm{L}^{-1}$ for silver.

The removal of toxic metals from aqueous solution can be achieved using different methods including ion exchange, ${ }^{4,5}$ reverse osmosis, ${ }^{6}$ chemical precipitation, ${ }^{7}$ and coagulation. ${ }^{8}$ Among the applicable methods, sorption has been recognized as the most optimum one due to its high efficiency, ease of implementation, and low cost. ${ }^{9-11}$ Sorption of aqueous metals can be realized by employing sorbents that contain functional

* To whom correspondence should be addressed. Tel.: +90 232750 7511. Fax: +90 232750 7509. E-mail: mdemir@iyte.edu.tr.

Izmir Institute of Technology.

Birzeit University. groups possessing metal binding ability such as amino, ${ }^{12}$ carboxyl,${ }^{13}$ phosphoric,,${ }^{14}$ mercapto,${ }^{15}$ amidoxime,,${ }^{16,17}$ and the like.

Chitosan is a nontoxic, biodegradable polymer derived from naturally occurring chitin, which is found in the exoskeleton of crustacean shells, such as crabs, insects, and shrimps. It is the largest biomass polysaccharide component along with starch. The main structure of chitin is the $\beta$-linked $N$-acetyl-Dglucosamine, and upon $N$-deacetylation, it is transformed into chitosan by thermochemical alkaline treatment. Chitosan $\left(\mathrm{C}_{6} \mathrm{H}_{11} \mathrm{NO}_{4}\right)_{n}$ has been widely reported as an effective sorbent of metal ions. It has a mass of $161 \mathrm{~g}$ per unit monomer and has a concentration of amino group $\left(-\mathrm{NH}_{2}\right)$ of $6.21 \mathrm{mmol} \cdot \mathrm{g}^{-1}$ if it is completely deacetylated. ${ }^{18}$ The extent of deacetylation controls the fraction of free amine groups and hydroxyl groups on chitosan. $^{2}$ To enhance the sorption capacity, physical and chemical methods ${ }^{19}$ have been used to modify this natural polysaccharide. Chitosan with different morphologies such as powder, ${ }^{20,21}$ bead, ${ }^{22-25}$ membrane, microsphere, ${ }^{26,27}$ fiber, ${ }^{28-30}$ and their cross-linked forms ${ }^{31-33}$ has been used to remove heavy metals from aqueous systems. The surface area of sorbents is known as the most important parameter in sorption studies. Larger surface area provides higher number of available active sites and results higher sorption activity. Therefore, attempts have been made to increase the surface area of chitosan sorbent. For example, drying in supercritical $\mathrm{CO}_{2}$ was used as a method to improve surface area of chitosan structures. ${ }^{34}$ Application of this process allows the generation of porosity and enlarges the surface area (close to $110 \mathrm{~m}^{2} \cdot \mathrm{g}^{-1}$ ) to be potentially used in catalysis. ${ }^{35}$

Among other diverse fields, water treatment is an important field that can benefit from the advances in nanoscale science and engineering. Nanotechnology-based products that are capable of reducing the concentrations of toxic compounds to sub-ppb levels can enhance water quality standards and sanitations. Fibrous materials prepared by the electrospinning process are increasingly attracting attention in this field due to the 

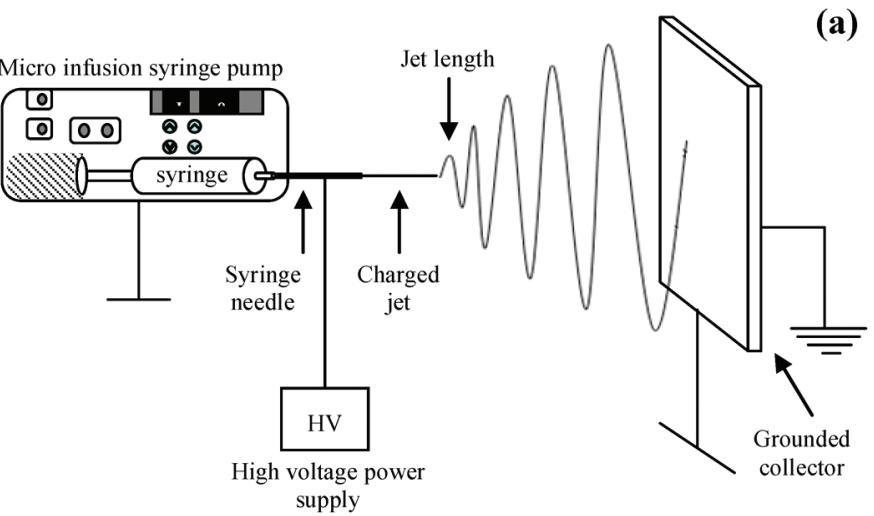

(a)

(b)

Figure 1. Schematic representation of (a) electrospinning setup, and (b) photographic image of the resulting fiber mat.

structural advantages conveyed by the nanosized diameter of the constituent fibers. The fiber diameter can be controlled by solution properties (viscosity, conductivity, and surface tension) and instrumental parameters (applied electrical field and flow rate) of the electrospinning process. ${ }^{36,37}$ The fibers exhibit high mechanical integrity, which is a desired property for filtration process under continuous flow. Moreover, the nanosized diameters of fibers provide much enhanced functionalities that cannot be obtained by bulk materials. ${ }^{38}$ Along with filtration, ${ }^{30,39}$ electrospun fibers can be used in potential and existing technologies such as biosensors, ${ }^{40}$ drug delivery, ${ }^{41}$ wound dressing, ${ }^{42}$ and protective clothing. ${ }^{43}$ Although the filtration efficiency of chitosan and chitosan derivatives has been known for many years, the studies that focus on the efficiency of electrospun chitosan fibers are scarce. Previously, electrospun chitosan fibers were applied for the removal of chromium ion. ${ }^{29}$ Chitosan was blended with poly(ethyleneoxide) (PEO) in solution to improve its processability in electrospinning process. While PEO brings electrospinnability to the blend system, the binding ability of metal ions in filtration process was attributed to chitosan. The blending of the similar material components was also used for removal of pathogenic microorganisms and $\mathrm{Cr}_{2} \mathrm{O}_{7}{ }^{2-}$ ions demonstrated by the same group of authors. ${ }^{28}$ Another interesting study related to metal ion filtration by electrospun chitosan fibers was reported by Park et al. ${ }^{30}$ The authors used chitosan itself without using additional material component like polyethylene oxide or polyvinyl alcohol. The dissolution of chitosan was achieved by trifluoroacetic acid (TFA), and electrospun fibers were neutralized by $\mathrm{K}_{2} \mathrm{CO}_{3}$. The chitosan fiber mats exhibited good erosion stability and high metal binding capacity in aqueous solution. In the present study, chitosan nanofiber mats were prepared via electrospinning. The filtration performance of the fiber material was then tested for $\mathrm{Fe}(\mathrm{III}), \mathrm{Cu}(\mathrm{II}), \mathrm{Ag}(\mathrm{I})$, and $\mathrm{Cd}(\mathrm{II})$ ions in aqueous solution. Both batch and microcolumn sorption methods were employed to characterize sorption over a range of experimental parameters.

\section{Experimental Section}

Materials and Methods. Medium molecular weight chitosan powder was used as received from Sigma-Aldrich and reagent grade glacial acetic acid and sodium chloride were obtained from Riedel-de Haen. Viscosimetry was employed for determination of molecular weight of the chitosan powder using the Mark-Houwink equation; $[\eta]=K M_{\mathrm{v}}^{\alpha}$, where $K$ and $\alpha$ are the specific constants for a given polymer and vary for the used solvent system and temperature. ${ }^{44}$ The constants, $K$ and $\alpha$ of chitosan were determined as $1.81 \times 10^{-3} \mathrm{~cm}^{3} \cdot \mathrm{g}^{-1}$ and 0.93 , respectively, when $0.20 \mathrm{M} \mathrm{NaCl} / 0.10 \mathrm{M}$ acetic acid solvent system were used. ${ }^{45,46}$ A Petrotest capillary viscosimeter (Dahlewitz, Germany) was used to measure the viscosity of chitosan/acid solution at $25^{\circ} \mathrm{C}$. The degree of deacetylation (DD) of chitosan was determined by titrimetric $^{47}$ and elemental analysis ${ }^{48}$ methods. The potentiometric method depends on the titration of chitosan with standardized $\mathrm{NaOH}$ (Merck) solution, used to deprotonate the positively charged amine groups in chitosan. For this purpose, $250.0 \mathrm{mg}$ portion of chitosan was dissolved in $10.0 \mathrm{~mL}$ of $0.30 \mathrm{M} \mathrm{HCl}$ (Merck) and after being diluted to $50.0 \mathrm{~mL}$ with ultra pure water, it was titrated with $0.100 \mathrm{M} \mathrm{NaOH}$ solution. The consumed volume of $\mathrm{NaOH}$, which corresponds to the amount of amine groups in chitosan is obtained from the difference between two inflection points of acid-base titration. Equation 1 describes the formulation used in the calculation of DD by the titrimetric method. In this equation, 161 is the molecular weight of glucosamine unit of chitosan, 42 is the difference in the molecular weights of chitin and chitosan repeating units, $m$ is the mass of the chitosan sample, $\Delta V$ is the volume, and $M$ is the molarity of $\mathrm{NaOH}$ solution. DD was also verified by elemental analysis after the determination of the elemental compositions of the samples by a LECO-CHNS-932 elemental analyzer (Mönchengladbach, Germany). Because deacetylation process removes two carbon atoms and one oxygen atom from chitin, chitosan differs in its $\mathrm{C}$ and $\mathrm{O}$ contents, while $\mathrm{N}$ remains unchanged. Therefore, $\mathrm{C} / \mathrm{N}$ ratios are used in the determination of DD. Equation 2 is used for the determination of DD where 5.145 is the ratio of $\mathrm{C} / \mathrm{N}$ in completely $\mathrm{N}$-deacetylated chitosan repeating unit and 1.671 is the difference between the $\mathrm{C} / \mathrm{N}$ ratios of chitin and chitosan.

$$
\begin{aligned}
& \mathrm{DD}=1-\frac{\left(1-161 \times \frac{\Delta V \times M}{m}\right)}{\left(\frac{\Delta V \times M}{m} \times 42+1\right)} \\
& \mathrm{DD}=\left(1-\frac{\mathrm{C} / \mathrm{N}-5.145}{1.671}\right) \times 100
\end{aligned}
$$

Electrospinning of Chitosan. Chitosan solutions were prepared by dissolving chitosan powder $\left(M_{\mathrm{v}}=1096 \mathrm{kDa}\right.$ and $70-75 \%$ degree of deacetylation) in 1,1,1,3,3,3-hexafluoroisopropanol (HFIP; SigmaAldrich). The solutions were stirred for 2 days until homogeneous and clear solutions were achieved. It was then placed in a $20.0 \mathrm{~mL}$ syringe fitted with a metallic needle of $0.2 \mathrm{~mm}$ of inner diameter. The syringe was fixed horizontally on the microsyringe pump (LION WZ-50C6) and the electrode of the high voltage power supply (Gamma High Voltage Research, Ormond Beach, FL, U.S.A.) was attached to the metal needle tip. Figure 1 shows the schematic diagram of electrospinning setup and a photographic image of the resulting fiber mat. The concentration of chitosan was kept constant at $0.4 \mathrm{wt} \%$ of the solution. An electrical field of $1.1 \mathrm{kV} \cdot \mathrm{cm}^{-1}$ (the applied voltage, 8 $\mathrm{kV}$; the tip-to-collector distance, $7 \mathrm{~cm}$ ) was applied to the solution, and the deposition time was adjusted to obtain a dense film. The flow 
rate of the polymer solution was $0.8 \mathrm{~mL} \cdot \mathrm{h}^{-1}$, and the electrospinning was performed in a horizontal position at room temperature. A matlike film was obtained on the grounded aluminum plate. The electrospun fiber mat was removed easily, washed with acetone, and dried under vacuum at $60{ }^{\circ} \mathrm{C}$ overnight.

Structural Characterization of Electrospun Mat. The morphology of electrospun chitosan mat was characterized by a scanning electron microscope (SEM, Philips XL-30S FEG) after coating the sample with gold. The average fiber diameter was determined by the statistical treatment of the SEM images with the image processing software, ImageJ. ${ }^{49}$ The diameter distribution of the electrospun fibers was obtained by measuring at least 100 test fibers. The crystalline structure of the samples was analyzed using an X-ray diffractometer (Philips X'Pert Pro X-ray Diffractometer). Fourier transform infrared spectroscopy (FTIR) measurements of the samples were performed with PerkinElmer Spectrum 100 FTIR Spectrometer (Shelton, U.S.A.) with Pike Miracle single reflection horizontal attenuated total reflection (ATR) accessory. The surface area of the fiber sample was measured with a Micromeritics Gemini V Brunauer-Emmett-Teller (BET) analyzer with $\mathrm{N}_{2}$ gas.

Sorption Studies. The electrospun chitosan fiber mat was used as a sorbent for the removal of $\mathrm{Fe}(\mathrm{III}), \mathrm{Cu}(\mathrm{II}), \mathrm{Ag}(\mathrm{I})$, and $\mathrm{Cd}(\mathrm{II})$ ions from aqueous solution. Stock standard solutions $\left(1000.0 \mathrm{mg} \cdot \mathrm{L}^{-1}\right)$ were prepared by dissolving $\mathrm{FeCl}_{3} \cdot 6 \mathrm{H}_{2} \mathrm{O}$ (Merck), $\mathrm{CuSO}_{4} \cdot 5 \mathrm{H}_{2} \mathrm{O}$ (Riedelde Haen), $\mathrm{AgNO}_{3}$ (Sigma-Aldrich), and $\mathrm{CdCl}_{2}$ (Merck) in ultrapure water (18.2 M $\Omega$ ). The working standard concentrations of the ions were then obtained by serial dilution. The sorption experiments encompassed the effects of the sorbent amount, shaking time, initial ion concentration, and sorbent type on the extent of fixation of the aforementioned cations.

The chitosan fiber mats were immersed in $3.0 \mathrm{~mL}$ of $100.0 \mu \mathrm{g} \cdot \mathrm{L}^{-1}$ multielement solution (adjusted to $\mathrm{pH}$ of 6.0) and continuously shaken in a GFL 1083 water bath shaker (Burgwedel, Germany) equipped with a microprocessor. Following each of the batch experiments, the liquid solution was separated from the fiber sorbent by centrifugation and the supernatant phase was analyzed for its iron, copper, silver, or cadmium content using ICP-MS (Agilent 7500ce Series, Japan). The ICP-MS operating conditions are provided in Table S1 (Supporting Information).

In addition to batch sorption studies, microcolumn tests were also performed for the sake of comparison. These studies were employed using a homemade microcolumn system involving PTFE tubing with internal diameter of $1.5 \mathrm{~mm}$ and a height of $6.0 \mathrm{~cm}$. The substrate chitosan fibers were folded and immersed into the flexible tube. Cylindrically shaped small sponge pieces were squeezed into both ends of the tube such that chitosan fibers were sandwiched and the backpressure of the continuous flow was prevented. In each trial, a $3.0 \mathrm{~mL}$ aliquot was passed through the sorbent tube. Additional tubes connecting the microcolumn to peristaltic pump tubing were inserted at both ends of the columns. The flow rate of the solution was adjusted to $0.15 \mathrm{~mL} \cdot \mathrm{min}^{-1}$. This process was performed 13 times, consecutively. For the sake of control, parallel experiments were conducted by both batch and microcolumn tests, in which $\mathrm{Fe}(\mathrm{III}), \mathrm{Cu}(\mathrm{II}), \mathrm{Ag}(\mathrm{I})$, and $\mathrm{Cd}(\mathrm{II})$ ions free of chitosan fiber were used.

Metal solutions at concentrations of 5.0, 10.0, 25.0, 50.0, 100.0, 200.0, 500.0, and $1000.0 \mu \mathrm{g} \cdot \mathrm{L}^{-1}$ were prepared by serial dilution of $10.0 \mathrm{mg} \cdot \mathrm{L}^{-1}$ stock solutions of $\mathrm{Fe}(\mathrm{III}), \mathrm{Cu}(\mathrm{II}), \mathrm{Ag}(\mathrm{I})$, and $\mathrm{Cd}(\mathrm{II})$ ions. All samples and standard solutions were acidified by adding proper amounts of concentrated $\mathrm{HNO}_{3}$ to produce $1.0 \%(\mathrm{v} / \mathrm{v}) \mathrm{HNO}_{3}$ in the final solution. The percentage sorption and the metal ion concentration on the fibers were calculated using the following equations:

$$
\text { sorption } \%=\frac{C_{\mathrm{i}}-C_{\mathrm{f}}}{C_{\mathrm{i}}} \times 100
$$

$$
q(\mu \mathrm{g} / \mathrm{g})=\frac{\left(C_{\mathrm{i}}-C_{\mathrm{f}}\right) V}{M}
$$

where $C_{\mathrm{i}}$ is the initial concentration, $C_{\mathrm{f}}$ is the final concentration of the ions in solution $\left(\mu \mathrm{g} \cdot \mathrm{L}^{-1}\right), V$ is the solution volume $(\mathrm{L})$, and $M$ is the sorbent fiber amount $(\mathrm{g}) .^{39}$

The selectivity of the nanofiber mat against a certain cation was also examined. The selectivity is expressed in terms of the distribution coefficient $(D),{ }^{50}$ calculated using the equation below.

$$
D=\frac{\operatorname{mg} M^{n^{+}} / \mathrm{g} \text { of polymer adsorbent }}{\operatorname{mg} M^{n^{+}} \mathrm{mL} \text { of solution }}
$$

Attention was paid to measure the concentration of any residual fluoride ion that would potentially be desorbed from the electrospun mat into solution. The concentration of fluoride ion was followed by ion chromatography (IC).

\section{Results and Discussion}

Electrospinning of Chitosan and Structural Characterization of Electrospun Mat. Both solution and instrumental parameters of electrospinning were varied for a chitosan/HFIP system. The process was optimized as electrospinning of 0.4 wt $\%$ solution at an electric field of $1.1 \mathrm{kV} \cdot \mathrm{cm}^{-1}$ under a flow rate of $0.8 \mathrm{~mL} \cdot \mathrm{h}^{-1}$. Panels a and $\mathrm{b}$ of Figure 2 present SEM micrographs of powder and electrospun nanofibers of chitosan, respectively, at different magnifications. When the chitosan powder was electrospun, its morphology changed drastically from bulk into nonwoven fibrous material. Panel $\mathrm{c}$ shows diameter histogram and Gaussian distribution of the electrospun nanofibers. The fibers have uniform diameter with $42 \pm 15 \mathrm{~nm}$.

Electrospinning of chitosan from solution is problematic due to its limited solubility and the presence of high degree of intermolecular and intramolecular interactions. In particular, low surface tension solvents or solvent compositions have been frequently used for electrospinning of chitosan, for example, TFA and HFIP. ${ }^{51-53}$ However, the usage of these solvents with their volatile and corrosive nature may raise some environmental concern. Potential release of these molecules could be disadvantageous and limit the applicability of the fibrous chitosan sorbent in water treatment. To figure out the content of HFIP in our particular system, the decantate was analyzed after sorption experiments using ion chromatography (IC). The results of measurements showed that the concentration of fluoride ion is around $0.022 \mathrm{mg} \cdot \mathrm{L}^{-1}$. This concentration is 2 orders of magnitude lower than the threshold set by World Health Organization (WHO; $\left.1.5 \mathrm{mg} \cdot \mathrm{L}^{-1}\right){ }^{54}$ Consequently, this level of fluoride is not risky, as expected, at least for the sorbent amount employed.

Nitrogen adsorption/desorption measurements were conducted to determine the BET surface area of the fibers. The shapes of the isotherms for powder and electrospun fibers are provided in panel a of Figure 3. Increasing the relative pressure does not vary the quantity of $\mathrm{N}_{2}$ adsorbed on chitosan powder, however, a linear increase in adsorbed $\mathrm{N}_{2}$ is observed for electrospun fibers. At a given temperature the isotherms for the chitosan nanofibers and the powders have a different shape. This difference can be explained by the larger effective surface area in fibrous electrospun mat compared to the powder. The BET surface area is calculated from the isotherms to be about 0.92 $\mathrm{m}^{2} \cdot \mathrm{g}^{-1}$ for the powder and $22.4 \mathrm{~m}^{2} \cdot \mathrm{g}^{-1}$ for the electrospun fibers, that is, more than a 20 -fold increase of the surface area of chitosan was observed upon electrospinning. Increasing the 

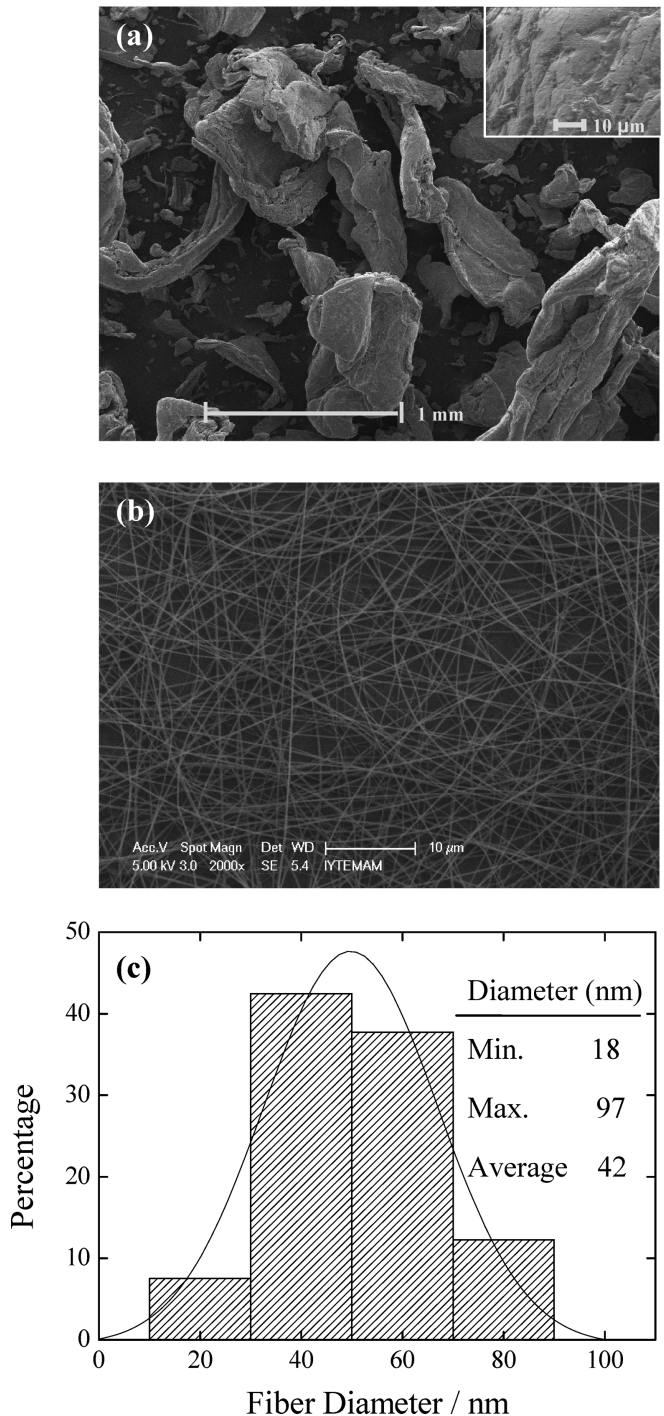

Figure 2. SEM micrographs of (a) chitosan powder, (b) electrospun mat, and (c) diameter histogram of the electrospun nanofibers.

surface area results in a higher fraction of sites of the sorbent being exposed at the solid-liquid interface that can readily bind to the metal ions.

The X-ray diffraction pattern of chitosan powder is given in Figure $3 \mathrm{~b}$. Two prominent reflections at 10 and $20^{\circ}$ are evident. These signals, which are in agreement with the literature, ${ }^{52}$ can be attributed to hydrated crystals of chitosan. The crystalline form of chitosan powder disappears upon electrospinning, indicating that the resulting fibers have amorphous texture. Because rapid solidification takes place during the process, the stretched molecular chains do not have enough time to align into three-dimensional ordered crystal structures. ${ }^{55}$

Figure $3 \mathrm{c}$ demonstrates the FTIR spectra of chitosan powder and electrospun chitosan nanofibers. Both spectra contain broad $-\mathrm{OH}$ stretching absorption bands between 3600 and $3300 \mathrm{~cm}^{-1}$. The absorption band observed between 3000 and $2800 \mathrm{~cm}^{-1}$ is attributed to the aliphatic $\mathrm{C}-\mathrm{H}$ stretching. In the carbonyl region of both spectra, the absorption band centered at around 1400 $\mathrm{cm}^{-1}$ is a characteristic band of chitin. The presence of these signals indicates that $N$-acetyl amino groups of chitin are still present in the system, that is, chitosan is not completely deacetylated. The percent of deacetylation was determined as $70-75 \%$, as mentioned in the Experimental Section, indicating that $25-30 \%$ of the repeating glucose units remain in acetylated
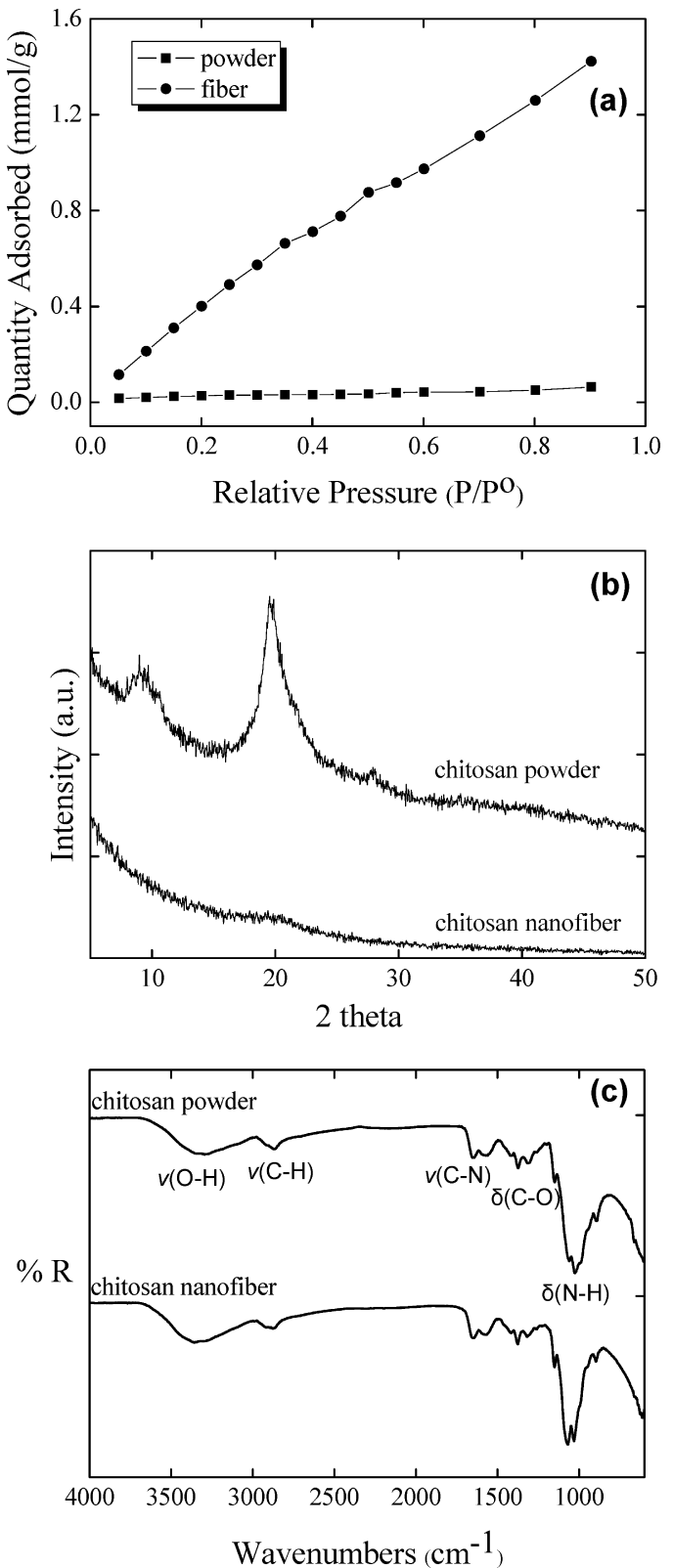

Figure 3. Structural characterization of the chitosan powder and electrospun chitosan fibers by means of (a) BET isotherm data, (b) X-ray diffraction patterns, (c) ATR-FTIR spectra.

form. A characteristic group of a free primary amino group $\left(-\mathrm{NH}_{2}\right)$ at the $\mathrm{C} 2$ position of glucosamine is present in chitosan. The band related with the bending of this group is identified within the spectral range of $1200-1000 \mathrm{~cm}^{-1}$.

Sorption Studies. Figure $4 \mathrm{a}$ shows the sorption percentage of $\mathrm{Fe}(\mathrm{III}), \mathrm{Cu}(\mathrm{II}), \mathrm{Ag}(\mathrm{I})$, and $\mathrm{Cd}(\mathrm{II})$ ions onto a chitosan nanofiber mat in a $100.0 \mu \mathrm{g} \cdot \mathrm{L}^{-1}$ synthetic multielement solution as a function of sorbent amount. The experiments were conducted at $\mathrm{pH}$ of 6.0 to prevent the formation of metal hydroxides at higher $\mathrm{pH}$ values. Lower $\mathrm{pH}$ values were also avoided due to possible dissolution of chitosan fibers as a result of protonation of the amine groups. As the sorbent amount increases, the sorption percentage of the ions increases slightly. This observation may be explained as follows. Electrospun fibers are randomly distributed as independent filaments without having preferential alignment. When fibers stay for a long time in solution under shaking, the fibers assemble into fiber bundles. The mechanism of this process is not fully understood in literature. ${ }^{56}$ However, it is regarded as disadvantageous because 

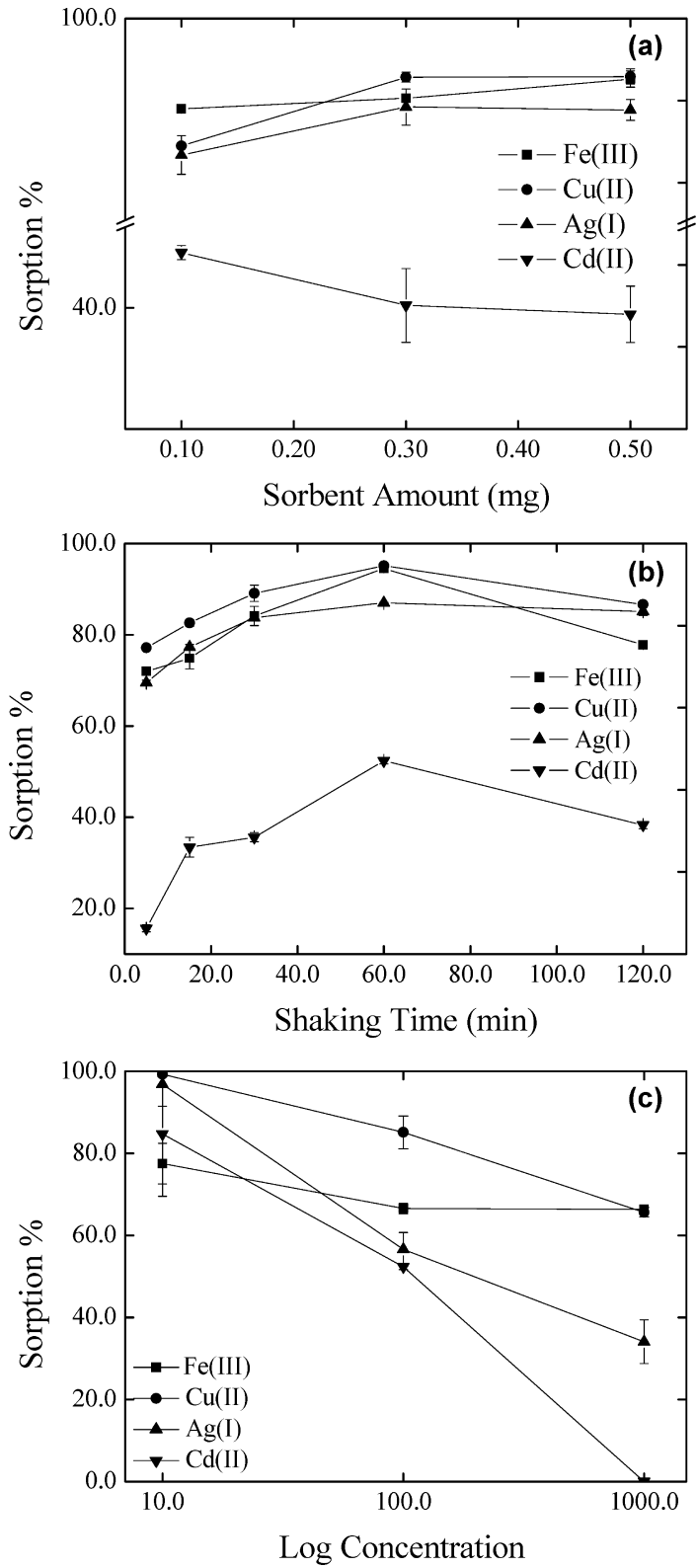

Figure 4. Effects of (a) sorbent amount, (b) shaking time, and (c) initial metal ion concentration on the sorption of $\mathrm{Fe}(\mathrm{III}), \mathrm{Cu}(\mathrm{II}), \mathrm{Ag}(\mathrm{I})$, $\mathrm{Cd}$ (II) on chitosan nanofibers at $\mathrm{pH}=6$.

it leads to the decrease of the surface-to-volume ratio of the system. Assembling of sorbents will yield a reduction in the specific surface area and an increase in the kinetic (diffusion) barrier against sorption of aqueous ions, hence, hindering the effectiveness of the sorbent entities and lowering the efficiency of sorption. Because the production of electrospinning is slow, the smallest amount of chitosan nanofiber sorbent $(0.10 \mathrm{mg})$ was fixed in all experiments. Another tentative explanation for reduction in sorption at high sorbent amount could be the aggregation of sorbent entities. It is generally assumed that the sorbent ions are individually and homogeneously dispersed in the solution medium. However, this might not always be the case. Such presumed aggregation will reduce the area of contact between the sorbent and solution medium, thus, decreasing the extent of sorption. In addition, kinetically, any plausible aggregation will slow down sorption due to imposing further surface diffusion necessity on the sorbed ions.

The percentage sorption at different shaking times is illustrated in Figure 4b. As expected, the extent of sorption of

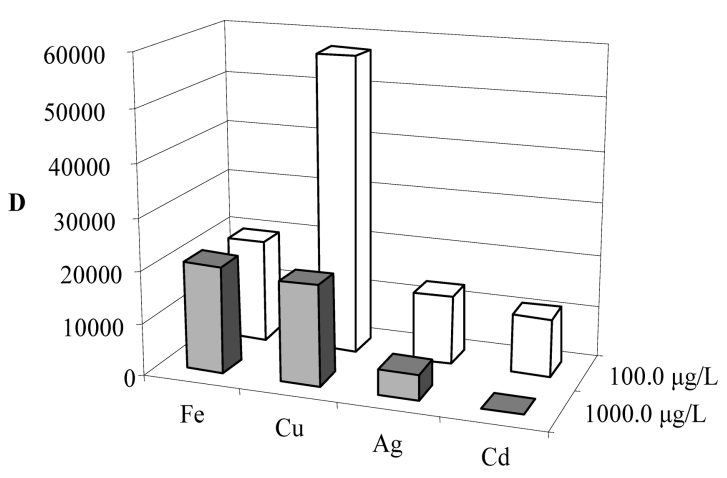

Figure 5. Sorption selectivity of chitosan nanofibers for the indicated metal ions at two different initial concentrations.

$\mathrm{Fe}(\mathrm{III}), \mathrm{Cu}(\mathrm{II}), \mathrm{Ag}(\mathrm{I})$, and $\mathrm{Cd}(\mathrm{II})$ increased with shaking time and maximum sorption was achieved for each metal ion at about $60 \mathrm{~min}$ of contact time. Prolonged exposure to $120 \mathrm{~min}$ resulted in slight decrease in sorption, probably due to desorption of some weakly bonded ions. The loading percentage of chitosan nanofiber sorbent was approximately $95 \%$ for copper, $94 \%$ for iron, $87 \%$ for silver, and $52 \%$ for cadmium in the 60 min contact period.

The effect of initial concentration of metal ions on the sorption behavior of chitosan nanofiber mat was determined for the concentrations of $0.01 \mathrm{mg} \cdot \mathrm{L}^{-1}, 0.1 \mathrm{mg} \cdot \mathrm{L}^{-1}$, and $1.0 \mathrm{mg} \cdot \mathrm{L}^{-1}$. The results, given in Figure 4c, indicate that, except for Fe(III), the sorption of metal ions decreased almost linearly with the increase in the initial metal ion concentration. The percentage sorption of $\mathrm{Fe}(\mathrm{III})$ was higher than 65 for all the concentrations tried. Maximum sorption percentages of $99 \%$ for copper, $97 \%$ for silver, $85 \%$ for cadmium, and $78 \%$ for iron were obtained at $0.01 \mathrm{mg} \cdot \mathrm{L}^{-1}$, where the concentration of the analyte is not sufficiently high to saturate all available functional sites. Increasing the initial concentration to higher value resulted in differences in affinity of the sorbent toward the analytes. As it is usually the case, increasing the initial concentration caused a decrease in percentage sorption. Increasing the ion concentration causes a larger competition of the ions to reach the limited number of functional groups, with the ions accommodated by these groups being usually smaller in number compared to ions remaining in solution.

The selectivity of the sorbent against the metal ions was also examined. Figure 5 gives the distribution coefficients $(D),{ }^{50}$ for $\mathrm{Fe}(\mathrm{III}), \mathrm{Cu}(\mathrm{II}), \mathrm{Ag}(\mathrm{I})$, and $\mathrm{Cd}(\mathrm{II})$ ions, which were determined under competitive conditions. These coefficients are frequently used as a measure of the capacity of a sorbent toward the sorbates. The order of decreasing selectivity at $100.0 \mu \mathrm{g} \cdot \mathrm{L}^{-1}$ is $\mathrm{Cu}>\mathrm{Fe}>\mathrm{Ag}>\mathrm{Cd}$, whereas, at $1.0 \mathrm{mg} \cdot \mathrm{L}^{-1}$, the order becomes $\mathrm{Cu} \cong \mathrm{Fe}>\mathrm{Ag}>\mathrm{Cd}$. The distribution coefficients of $\mathrm{Cu}$ and $\mathrm{Ag}$ are 3-fold larger at $100.0 \mu \mathrm{g} \cdot \mathrm{L}^{-1}$ than at $1.0 \mathrm{mg} \cdot \mathrm{L}^{-1}$. Thus, the concentration of the analyte is significantly effective for the selectivity of the sorbent toward the analytes of interest.

The extent of removal of metal ions pertains directly to the operating mechanism. The sorption mechanism on chitosan is quite complicated. It depends basically on the structural properties of the polymer (like the number of monomer units, the degree of deacetylation, crystallinity, etc.). Moreover, the structural parameters are reported to affect the equilibrium and kinetic aspects of sorption. ${ }^{57}$ The speciation of the metal ions under the prevailing experimental conditions is another important parameter in determining the sorption mechanism. Under neutral-slightly basic $\mathrm{pH}$ conditions, the major mechanism of metal sorption is binding to the free electron pair on amine 
groups. It is reported that chitosan has the highest chelating ability in comparison to other natural polymers obtained from seafood wastes and many other natural substances like activated sludge. ${ }^{58}$ Nevertheless, the contribution of hydroxyl groups to metal uptake can not be totally disregarded, especially under $\mathrm{pH}$ conditions, leading to deprotonation of these groups. In addition, the $\mathrm{pH}$ of the medium and the presence of ligands can change the speciation of the metal ion in a way that may result in turning the chelation mechanism into the electrostatic attraction mechanism. ${ }^{57}$

As reported previously in this work, the extent of metal sorption was studied at $\mathrm{pH}$ of 6.0. At such $\mathrm{pH}$, the deprotonation of amino and hydroxyl groups is not plausible, and as a result, the metal ions seem to be fixed mainly by coordination to amine groups. The extent of such complexation is closely related to the speciation of those ions, their charge density, and electronic structure. Under the $\mathrm{pH}$ of our experiments, speciation analysis using Visual MINTEQ (version 2.53) program suggests that the ions are expected to exist primarily in their "bare" form $\mathrm{Ag}^{+}$, $\left.\mathrm{Cu}^{2+}, \mathrm{Cd}^{2+}, \mathrm{Fe}(\mathrm{OH})^{2+}\right)$. Thus, as a first approximation, it seems that the charge density and electronic structure (availability of unsaturated d orbitals) will determine the extent of complexation. The coordination mechanism might explain the relatively lower sorption of $\mathrm{Ag}^{+}$and $\mathrm{Cd}^{2+}$ in comparison to the $\mathrm{Cu}^{2+}$ and $\mathrm{Fe}^{3+}$, as the $\mathrm{d}$ orbitals of $\mathrm{Ag}^{+}$and $\mathrm{Cd}^{2+}$ are full. From this perspective, $\mathrm{Fe}^{3+}$ would be expected to have the highest affinity, which is in line with the results observed at the highest studied concentration, that is, $1.0 \mathrm{mg} \cdot \mathrm{L}^{-1}$.

The preferential sorption behavior can also be explained in terms of steric reasons, that is, ionic radii of the metal ions. The results obtained from the uptake of the metals throughout the study are in agreement with various results obtained with chitosan flakes that reported the same order of affinity for $\mathrm{Cu}^{2+}$ and $\mathrm{Cd}^{2+} \cdot{ }^{59,60}$ It might be said that sorption of $\mathrm{Cd}^{2+}$ and $\mathrm{Ag}^{+}$ is less favorable, probably due to their larger ionic radii, the thing that might create a mismatch to the binding sites on chitosan.

The mechanism can also be roughly viewed from another perspective. The liability of ions toward coordinative bonding with ligands can be explained based on the hard-soft acid base principle (HSAB). This approach provides general guidelines that qualitatively describe the ion-ligand coordinative bond stability in light of the relative sizes and charge densities of the potential partners. Smaller ions with higher charge densities tend to behave as hard acids and bind preferentially to ligands of smaller size that behave as hard bases. On the contrary, larger ions with smaller charge densities (soft acids) would preferentially bind to ligands that are diffuse and bulky (soft bases). In our particular case, the amine group on the backbone of chitosan chains plays the main role in sorption of metal ions and can be classified as a hard base. Based on HSAB principle, the amine ligand will preferentially bind to hard acids $\left(\mathrm{Fe}^{3+}\right.$ in this case) and demonstrate a low tendency toward binding with soft acids $\left(\mathrm{Ag}^{+}\right.$in this case), which is consisted with our experimental results. Both $\mathrm{Cu}^{2+}$ and $\mathrm{Cd}^{2+}$ are classified as borderline acids and, as such, their different sorption affinities to amine groups can not be explained based on this approach.

The differences in sorption characteristics for commercial chitosan flake and the prepared nanofiber are illustrated in Figure 6. As seen, higher sorption was observed for the fiber in all cases. This result illustrates the most prominent advantage of the fibers prepared. The higher sorption of the fiber can be attributed to the increased surface area $(22.4$

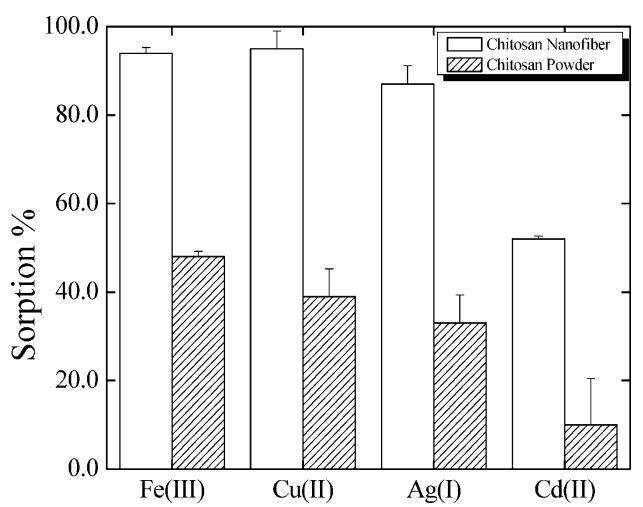

Figure 6. Comparison of the sorption efficiency of chitosan powder and chitosan nanofiber.

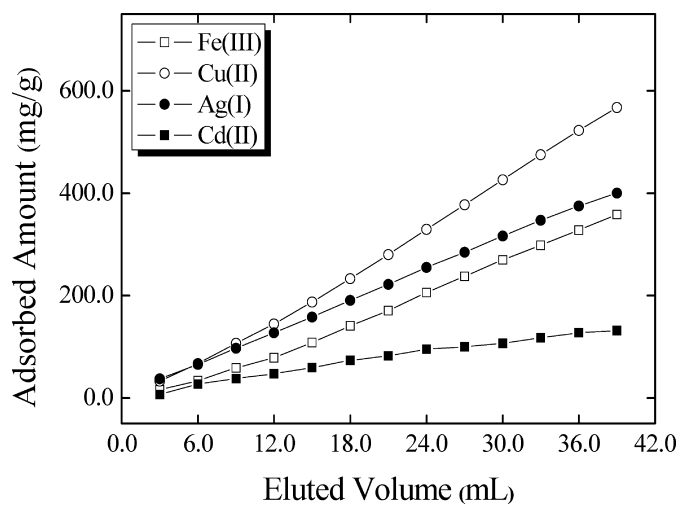

Figure 7. Microcolumn application of chitosan nanofiber mat on the sorption of $\mathrm{Fe}(\mathrm{III}), \mathrm{Cu}(\mathrm{II}), \mathrm{Ag}(\mathrm{I})$, and $\mathrm{Cd}(\mathrm{II})$. Note that each aliquot is $3 \mathrm{~mL}$.

$\left.\mathrm{m}^{2} \cdot \mathrm{g}^{-1}\right)$ in comparison with commercial chitosan $(0.92$ $\mathrm{m}^{2} \cdot \mathrm{g}^{-1}$ ); hence, a much larger number of functional groups (surface active sites) are readily available for sorption in the case of the fiber. In addition, the crystallinity of the prepared sorbent was completely different from that of commercial chitosan which may also affect the sorption properties of the fibers. ${ }^{61-63}$

To investigate the effect of temperature, two sets of sorption experiments were carried out at 25 and $50{ }^{\circ} \mathrm{C}$. The obtained data was used to evaluate the apparent thermodynamic parameters of sorption, as presented in Table S2, using a series of thermodynamic expressions. ${ }^{64}$

The extent of sorption of the metal ions decreases as the temperature of the system increases, demonstrating an exothermic sorption behavior. This result is in line with the one reported earlier for As sorption on chitosan. ${ }^{65}$ The $\Delta S^{\circ}$ values for $\mathrm{Fe}(\mathrm{III}), \mathrm{Cu}(\mathrm{II}), \mathrm{Ag}(\mathrm{I})$, and $\mathrm{Cd}(\mathrm{II})$ were found to be positive indicating that the system gains more entropy upon fixation of the ions. This could be resulting from dehydration steps of the ions upon sorption. The combination of $\Delta H^{\circ}$ and $\Delta S^{\circ}$ values yields negative $\Delta G^{\circ}$ values, which characterizes situations in which the reaction products are favored over the reactants.

To investigate the applicability of the sorbents for column sorption studies, similar experiments were conducted with nanofiber-filled microcolumn. The sorption results obtained via column application are illustrated in Figure 7 . These tests signify the adequacy of the prepared chitosan nanofibers for continuous removal of $\mathrm{Fe}(\mathrm{III}), \mathrm{Cu}(\mathrm{II}), \mathrm{Ag}(\mathrm{I})$, and $\mathrm{Cd}(\mathrm{II})$ from aqueous solutions. The first eluted $3.0 \mathrm{~mL}$ aliquots did not show significant differences in the extent of sorption of the 
studied ions, while a further increase in solution volume significantly enhanced the difference between the sorbed amounts of the metal ions. $\mathrm{Fe}(\mathrm{III}), \mathrm{Cu}(\mathrm{II})$, and $\mathrm{Ag}(\mathrm{I})$ ions did not demonstrate sorption maxima after $39.0 \mathrm{~mL}$ of solution volume. This result states that the fibers are still active in sorption, even after 13 repetitions of elution (thanks to electrospinning). On the other hand, $\mathrm{Cd}(\mathrm{II})$ ions almost reached maximum sorption. The lower sorption of $\mathrm{Cd}(\mathrm{II})$ was probably not related with saturation of the available functional groups and may have resulted from different kinetic details and sorption mechanism in comparison to the other ions. A further investigation is required to clarify this issue. In addition, for $\mathrm{Fe}(\mathrm{III})$ and $\operatorname{Ag}(\mathrm{I})$ ions, the affinity of the nanofiber toward each ion is different from that observed in batch-type sorption, while $\mathrm{Cu}(\mathrm{II})$ and $\mathrm{Cd}(\mathrm{II})$ show similar behavior with batch sorption studies.

\section{Conclusion}

Electrospinning of the biopolymer chitosan is a difficult procedure due to its limited solubility in most organic solvents and strong inter- and intrachain hydrogen bonding that leads to an increase in viscosity of solution even at a low weight fraction. In this study, a uniform diameter of nanosized electrospun chitosan fibers were successfully fabricated by using medium molecular weight chitosan dissolved in HFIP. It was shown that chitosan nanofibers can be applied in the continuous removal of several metal ions. The environmentally friendly chitosanbased nanofibrous filter material has prominent benefits due to the high surface area per unit mass, resulting from the very fine diameter. The results of the sorption study showed that shaking time, metal ion concentration, and temperature have strong influence on the sorption of $\mathrm{Fe}(\mathrm{III}), \mathrm{Cu}$ (II), $\mathrm{Ag}(\mathrm{I})$, and $\mathrm{Cd}(\mathrm{II})$ on chitosan nanofiber mat. In addition, $\mathrm{Cu}$ (II) was selectively filtered in contrast to $\mathrm{Cd}(\mathrm{II})$. Because the fibers are integrated to each other in a dense polymeric film, the chitosan nanofiber mat can be used as a sorbent for solid phase extraction (SPE) cartridges.

Acknowledgment. The authors acknowledge The Environmental Research Center and The Center of Material Research at IYTE for assistance in all measurements.

Supporting Information Available. SEM image of fibers after a set of sorption studies, ICP-MS operation parameters, and thermodynamic parameters of chitosan nanofibers in sorption. This material is available free of charge via the Internet at http://pubs.acs.org.

\section{References and Notes}

(1) Benguella, B.; Benaissa, H. Water Res. 2002, 36, 2463-2474.

(2) Ngah, W. S. W.; Endud, C. S.; Mayanar, R. React. Funct. Polym. 2002, 50, 181-190.

(3) Cho, B.-Y. Process Biochem. (Amsterdam, Neth.) 2005, 40, 3314 3320.

(4) Lee, S.-T.; Mi, F.-L.; Shen, Y.-J.; Shyu, S.-S. Polymer 2001, 42, 18791892.

(5) Ngah, W. S. W.; Fatinathan, S. J. Environ. Sci. (Beijing, China) 2010, 22, 338-346.

(6) Yang, T.; Zall, R. R. J. Food Sci. 1984, 49, 91-93.

(7) Chemical Precipitation; U.S. Environmental Protection Agency: Washington, DC, 2000; EPA832-F-00-018.

(8) Assaad, E.; Azzouz, A.; Nistor, D.; Ursu, A. V.; Sajin, T.; Miron, D. N.; Monette, F.; Niquette, P.; Hausler, R. Appl. Clay Sci. 2007, 37, 258-274.

(9) Li, N.; Bai, R. Sep. Purif. Technol. 2005, 42, 237-247.

(10) Ng, J. C. Y.; Cheung, W. H.; Mckay, G. J. Colloid Interface Sci. 2002, 255, 64-74.
(11) Justi, K. C.; Favere, V. T.; Larenjeira, M. C.; Neves; Peralta, R. A. J. Colloid Interface Sci. 2005, 291, 369-374.

(12) Li, J.; Miao, X.; Hao, Y.; Zhao, J.; Sun, X.; Wang, L. J. Colloid Interface Sci. 2008, 318, 309-314.

(13) Wong, K. K.; Lee, C. K.; Low, K. S.; Haron, M. J. Chemosphere 2003, 50, 23-28.

(14) Puziy, A. M.; Poddubnaya, O. I.; Zaitsev, V. N.; Konoplitska, O. P. Appl. Surf. Sci. 2004, 221, 421-429.

(15) Mondal, B. C.; Das, A. K. Bull. Chem. Soc. Jpn. 2003, 76, 111114.

(16) Nilchi, A.; Babalou, A. A.; Rafiee, R.; Kalal, H. S. React. Funct. Polym. 2008, 68, 1665-1670.

(17) Saeed, K.; Haider, S.; Oh, T.-J.; Park, S.-Y. J. Membr. Sci. 2008 , 322, 400-405.

(18) Wu, F.-C.; Tseng, R.-L.; Juang, R.-S. J. Environ. Manage. 2010, 9 , $1798-806$.

(19) Miretzky, P.; Cirelli, A. F. J. Hazard. Mater. 2009, 167, 10-23.

(20) Gamage, A.; Shahidi, F. Food Chem. 2007, 104, 989-996.

(21) Juang, R.-S.; Shiau, R.-C. J. Membr. Sci. 2000, 165, 159-167.

(22) Ngah, W. S. W.; Fatinathan, S. Chem. Eng. J. (Amsterdam, Neth.) 2008, 143, 62-72.

(23) Li, N.; Bai, R.; Liu, C. Langmuir 2005, 21, 11780-11787.

(24) Lee, M.-Y.; Hong, K.-J.; Kajiuchi, T.; Yang, J.-W. Int. J. Biol. Macromol. 2005, 36, 152-158.

(25) Twu, Y.-K.; Huang, H.-I.; Chang, S.-Y.; Wang, S.-L. Carbohydr. Polym. 2003, 54, 425-430.

(26) Vieira, R. S.; Beppu, M. M. Water Res. 2006, 40, 1726-1734.

(27) Zhou, L.; Liu, J.; Liu, Z. J. Hazard. Mater. 2009, 172, 439-446.

(28) Desai, K.; Kit, K.; Li, J.; Davidson, P. M.; Zivanovic, S.; Meyer, H. Polymer 2009, 50, 3661-3669.

(29) Desai, K.; Kit, K.; Li, J.; Zivanovic, S. Biomacromolecules 2008, 9 , $1000-1006$

(30) Haider, S.; Park, S.-Y. J. Membr. Sci. 2009, 328, 90-96.

(31) Chen, A.-H.; Liu, S.-C.; Chen, C.-Y.; Chen, C.-Y. J. Hazard. Mater. 2008, 154, 184-191.

(32) Ngah, W. S. W.; Ghani, S. A.; Kamari, A. Bioresour. Technol. 2005, 96, 443-450.

(33) Vieira, R. S.; Beppu, M. M. Colloids Surf., A 2006, 279, 196-207.

(34) Okamoto, H.; Nishida, S.; Todo, H.; Sakakura, Y.; Iida, K.; Danjo, K. J. Pharm. Sci. 2003, 92, 371-380.

(35) Valentin, R.; Molvinger, K.; Quignard, F.; Brunel, D. New J. Chem. 2003, 27, 1690-1692.

(36) Demir, M. M.; Yilgor, I.; Yilgor, E.; Erman, B. Polymer 2002, 43, 3303-3309.

(37) Demir, M. M.; Gulgun, M. A.; Menceloglu, Y. Z.; Erman, B.; Abramchuk, S. S.; Makhaeva, E. E.; Khokhlov, A. R.; Matveeva, V. G.; Sulman, M. G. Macromolecules 2004, 37, 1787-1792.

(38) Greiner, A.; Wendorff, J. H. Angew. Chem., Int. Ed. 2007, 46, 56705703.

(39) Sang, Y.; Li, F.; Gu, Q.; Liang, C.; Chen, J. H. Desalination 2008, $223,349-360$.

(40) Frey, M. W.; Baeumner, A. J.; Li, D.; Kakad, P. U.S. Patent 7,485,591 B2, 2009.

(41) Jiang, H.; Fang, D.; Hsiao, B. S.; Chu, B.; Chen, W. Biomacromolecules 2004, 5, 326-333.

(42) Chen, J. P.; Chang, G.-Y.; Chen, J.-K. Colloids Surf., A 2008, 313314, 183-188.

(43) Yarin, A. L.; Zussman, E. Complex and Smart Fluids, Meeting Abstract, FM4L_10932, XXI ICTAM, 2004.

(44) Planas, M. R. Ph.D. Thesis, Universitat Polytecnica de Catalunya, 2002.

(45) Taghizadeh, S. M.; Davari, G. Carbohydr. Polym. 2006, 64, 9-15.

(46) Kasaai, M. R. Carbohydr. Polym. 2007, 68, 477-488.

(47) Tolaimate, A.; Desbrieres, J.; Rhazi, M.; Alagui, A.; Vincendon, M.; Vottero, P. Polymer 2000, 41, 2463-2469.

(48) Kasaai, M. R.; Arul, J.; Charlet, G. J. Polym. Sci., Part B: Polym. Phys. 2000, 38, 2591-2598.

(49) Public domain software to be downloaded from National Institute of Health http://rsb.info.nih.gov/ij.

(50) Rodrigues, A. E. Ion Exchange Science and Technology; Martinus Nijhoff Publishers: Leiden, Netherlands, 1986; Nato ASI-Series 107, p 35.

(51) Sangsanoh, P.; Supaphol, P. Biomacromolecules 2006, 7, 27102714.

(52) Schiffman, J. D.; Stulga, L. A.; Schauer, C. L. Polym. Eng. Sci. 2009, 49, 1918-1928.

(53) Ohkawa, K.; Cha, D.; Kim, H.; Nishida, A.; Yamamoto, H. Macromol. Rapid Commun. 2004, 25, 1600-1605. 
(54) Guidelines for Drinking-Water Quality, Recommendations, 3rd ed.; World Health Organization: Geneva, 2004; Vol. 1.

(55) Zhou, Y. S.; Yang, D.; Chen, X.; Xu, Q.; Lu, F.; Nie, J. Biomacromolecules 2008, 9, 349-354.

(56) Demir, M. M.; Ugur, G.; Gulgun, M. A.; Menceloglu, Y. Z. Macromol. Chem. Phys. 2008, 209, 508-515.

(57) Guibal, E. Sep. Purif. Technol. 2004, 38, 43-74.

(58) Varma, A. J.; Deshpande, S. V.; Kennedy, J. F. Carbohydr. Polym. 2004, 55, 77-93.

(59) Bassi, R.; Prasher, S. O.; Simpson, B. K. Sep. Sci. Technol. 2000, 35, $547-560$.

(60) Rhazi, M.; Desbrieres, J.; Tolaimate, A.; Rinaudo, M.; Vottero, P.; Alagui, A.; El Meray, M. Eur. Polym. J. 2002, 38, 1523-1530.
(61) Guibal, E.; Larkin, A.; Vincent, T.; Tobin, J. M. Ind. Eng. Chem. Res. 1999, 38, 4011-4022.

(62) Milot, C.; Mcbrien, J.; Allen, S.; Guibal, E. J. Appl. Polym. Sci. 1998, 68, 571-580.

(63) Piron, E.; Domard, A. Int. J. Biol. Macromol. 1998, 22, 33-40.

(64) Shahwan, T.; Erten, H. N.; Unugur, S. J. Colloid Interface Sci. 2006, 300, 447-452.

(65) Boyac1, E.; Eroğlu, A. E.; Shahwan, T. Talanta 2010, 80, $1452-1460$.

BM100755X 